Check for updates

Cite this: RSC Adv., 2019, 9, 14143

Received 19th February 2019

Accepted 29th April 2019

DOI: 10.1039/c9ra01271k

rsc.li/rsc-advances

\section{Antibiotic removal by agricultural waste biochars with different forms of iron oxide}

\author{
Yue Chen, ${ }^{a}$ Jing Shi, (D)*ab Qiong Du, ${ }^{a}$ Haowen Zhang ${ }^{a}$ and Yixin Cui ${ }^{a}$ \\ Pollution by antibiotics has become a serious threat to public health. In this study, agricultural waste, corn husk, in \\ the form of biochar, was utilized for antibiotic removal from wastewater. Two kinds of iron-loaded biochars, \\ impregnation-pyrolysis biochar (IP) and pyrolysis-impregnation biochar (PI), were synthesized to adsorb the \\ typical antibiotics tetracycline (TC) and levofloxacin (LEV). PI contained amorphous hydrated iron oxide, whereas \\ the major component of IP was $\gamma-\mathrm{Fe}_{2} \mathrm{O}_{3}$. Compared with IP, PI had a much higher adsorption capacity for \\ both TC and LEV. This was because PI could provide more $-\mathrm{OH}$, especially $-\mathrm{OH}_{\text {ads, }}$ to serve as the adsorption \\ sites. In comparison with TC, $-\mathrm{OH}$ was prone to combine with LEV. FT-IR and XPS results indicated that the \\ mechanisms of LEV adsorption included hydrogen bonding, F-replacement, electrostatic attraction and bridging \\ bidentate complexation. TC adsorption may involve complexation, hydrogen bonding and electrostatic attraction.
}

\section{Introduction}

Antibiotics are extensively used in treating infective diseases for both humans and animals. Levofloxacin (LEV) and tetracycline (TC) (Fig. 1) are two typical and commonly used antibiotics. LEV is a fluoroquinolone antibiotic, which is generally utilized to treat gastrointestinal tract, genitourinary and respiratory infections. ${ }^{1}$ TC is used for the treatment of inflammatory bowel disease and acne. ${ }^{2}$ However, owing to the improper treatment of pharmaceutical wastewater, its abuse in food additives used for livestock breeding or animal husbandry, and incomplete metabolism in human and animal bodies, excessive antibiotics are discharged into the environment. ${ }^{3}$ As a result, they have been frequently detected in different environments and even in drinking water. Animals and humans could absorb excess environmental antibiotics through the water and food chains, resulting in antibiotic resistance. ${ }^{4,5}$ On the other hand, the conventional biological wastewater treatment was not appropriate for antibiotic removal, due to their toxic effects on microorganisms. ${ }^{4}$ Consequently, cost-effective approaches for LEV and TC removal from wastewater are urgently needed.

Adsorption is considered as one of the most applicable technologies because it is safety, economical and simple. Several adsorbents have been tested to adsorb LEV or TC, such as chitosan, montmorillonite, graphene-based materials. ${ }^{5,6}$ To achieve the aims of low-cost, corn husks, the agricultural waste, were selected as the major part of the adsorbent. It could not only reduce the antibiotics pollution but also supply an additional method for corn husks reuse. In addition, corn is

${ }^{a}$ School of Engineering, China Pharmaceutical University, Nanjing 211198, People's Republic of China.E-mail: shijing_cpu@163.com

${ }^{b}$ Department of Civil Engineering, McMaster University, Hamilton L8S 4L7, Canada a worldwide and plentiful crop, which makes it cheap and easy to obtain. For adsorption capacity enhancement and recovery improvement, the corn husks were transformed into biochar and Fe, which was magnetic and non-toxic, was employed for the biochar modification. In summary, iron modified-biochars advocate the concept of disposal waste with waste. The corn husks are easy to obtain and cheap and they are harmless to the environment. In addition, they can remove antibiotics highefficiently from aqueous solution. Furthermore, they can be recycled and reuse, which still maintains high adsorption capacities.

In this study, two kinds of Fe-loaded biochars with different forms of Fe oxide were prepared for LEV and TC removal. The adsorption performances were investigated and compared. The possible adsorption mechanisms were analyzed based on X-ray Diffraction (XRD), X-ray Photoelectron Spectroscopy (XPS) and Fourier Transform Infrared Spectroscopy (FTIR) results.

\section{Material and methods}

\subsection{Materials}

LEV $(>98.5 \%)$ and TC $(>98.5 \%)$ were purchased from TCI company. Corn husks were acquired from Shandong Province, China. The type of corn was Liangyu 99. Ferric chloride

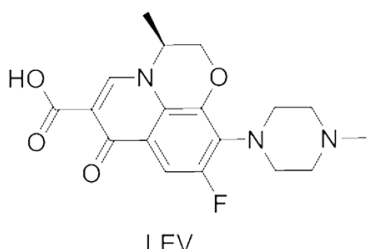

b

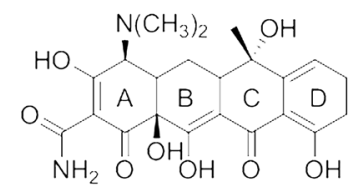

TC
Fig. 1 The structures of LEV (a) and TC (b) 
hexahydrate $\left(\mathrm{FeCl}_{3} \cdot 6 \mathrm{H}_{2} \mathrm{O}\right)$ and other chemicals were analytical grades and purchased from Aladdin company.

\subsection{The preparation of adsorbents}

The raw corn husks were washed with deionized water, and then dried in oven at $100 \pm 5{ }^{\circ} \mathrm{C}$ for $24 \mathrm{~h}$. After cooling down to room temperature, the corn husks were ground to 60-100 mesh with a disintegrator.

The modification for the two types of Fe-biochars both included the following three operations, but in a different order. (1) Impregnation: $40.545 \mathrm{~g} \mathrm{FeCl}_{3} \cdot 6 \mathrm{H}_{2} \mathrm{O}$ was dissolved into $500 \mathrm{~mL}$ deionized water, and put $8.377 \mathrm{~g}$ biomass into the solution (the mass ratio of total iron to biomass was $1: 1$ ). Then, the $\mathrm{pH}$ value was adjusted to 10 . The mixture was placed in a shaker for $2 \mathrm{~h}$ with $180 \mathrm{rpm}$ at $30{ }^{\circ} \mathrm{C}$, and next, $\mathrm{pH}$ was adjusted to 10 again. The obtained mixture was deposited at $70{ }^{\circ} \mathrm{C}$ for $0.5 \mathrm{~h}$. After cooling to room temperature, the solidliquid mixture was filtered and the obtained solid was dried at $60{ }^{\circ} \mathrm{C}$ for $12 \mathrm{~h}$. (2) Pyrolysis: the pyrolysis temperature was raised to $300{ }^{\circ} \mathrm{C}$ at a rate of $5{ }^{\circ} \mathrm{C} \min ^{-1}$ and maintained for $1 \mathrm{~h}$. During this process, nitrogen gas was passed over to isolate oxygen with the rate of $200 \mathrm{~mL} \mathrm{~min}^{-1}$ in the muffle furnace. After that, it was cooled to room temperature. (3) Drying: the solid residues were washed with distilled water and dried at $40{ }^{\circ} \mathrm{C}$.

If the corn husks were modified as the order above, it was defined as the impregnation-pyrolysis biochar (IP). If it was in the sequence of (2) (1) (3), the product was the pyrolysisimpregnation biochar (PI). The operation process was shown in Fig. 2.

\subsection{Adsorption experiments}

$0.04 \mathrm{~g}$ PI or IP was added to $50 \mathrm{~mL} 0.55 \mathrm{~mol} \mathrm{~L}^{-1} \mathrm{LEV}$ $\left(200 \mathrm{mg} \mathrm{L}^{-1}\right)$ or TC $\left(266 \mathrm{mg} \mathrm{L}^{-1}\right)$ solutions in a shaking water bath for $24 \mathrm{~h}$ at $120 \mathrm{rpm}$ and $30^{\circ} \mathrm{C}$, respectively. $\mathrm{pH}$ values were adjusted by $\mathrm{HCl}$ and $\mathrm{NaOH}$ solution. The adsorption kinetic and isotherm experiments were carried out under optimal initial $\mathrm{pH}$ values. In the kinetic experiments, samples were taken at different time intervals. Next, the supernatant was filtered through $0.22 \mu \mathrm{m}$ filter. Then the absorbance of the supernatant was measured using ultraviolet-visible spectrophotometer at $357 \mathrm{~nm}$ and $287 \mathrm{~nm}$ for TC and LEV, respectively. $^{7-10}$

To facilitate description, the adsorbed samples would be represented by abbreviations. For example, IP-LEV is the IP sample after LEV adsorption. The others were abbreviated similarly.

\subsection{Regeneration and reuse}

Five reuse cycles were performed to evaluate the regenerability of two modified biochars. $50 \mathrm{~mL} 0.55 \mathrm{~mol} \mathrm{~L}^{-1} \mathrm{LEV}\left(200 \mathrm{mg} \mathrm{L}^{-1}\right)$ or TC $\left(266 \mathrm{mg} \mathrm{L}^{-1}\right)$ solution was adsorbed first by $0.04 \mathrm{~g}$ PI or IP in a shaking water bath for $24 \mathrm{~h}$ at $120 \mathrm{rpm}$ and $30^{\circ} \mathrm{C}$, respectively. Afterward, they were regenerated by $25 \mathrm{~mL} 0.01 \mathrm{~mol} \mathrm{~L}^{-1}$ $\mathrm{NaOH}$ solution and shaken at $120 \mathrm{rpm}$ under $30{ }^{\circ} \mathrm{C}$ for $24 \mathrm{~h}$. Next, the regenerated adsorbents was washed with deionized water and dried at $105{ }^{\circ} \mathrm{C}$. The adsorbents were reused to remove TC or LEV for the next four cycle as described above.

\subsection{Materials characterization}

BET (Quantachrome, Autosorb-IQ-AG-MP) was used to explore the specific surface area and the micropore properties. The specific surface area of the modified biochars was determined by nitrogen adsorption method. ${ }^{11}$ The structure of the compounds was detected by XPS (Thermo Fisher Scientific, Escalab 250Xi) using mono-chromatized $\mathrm{Al} \mathrm{K \alpha} \mathrm{X-ray} \mathrm{source} \mathrm{with}$ a power of $100 \mathrm{~W}$ and pass energy of $30 \mathrm{eV} \cdot{ }^{12,13} \mathrm{XRD}$ (Bruker-Axs,
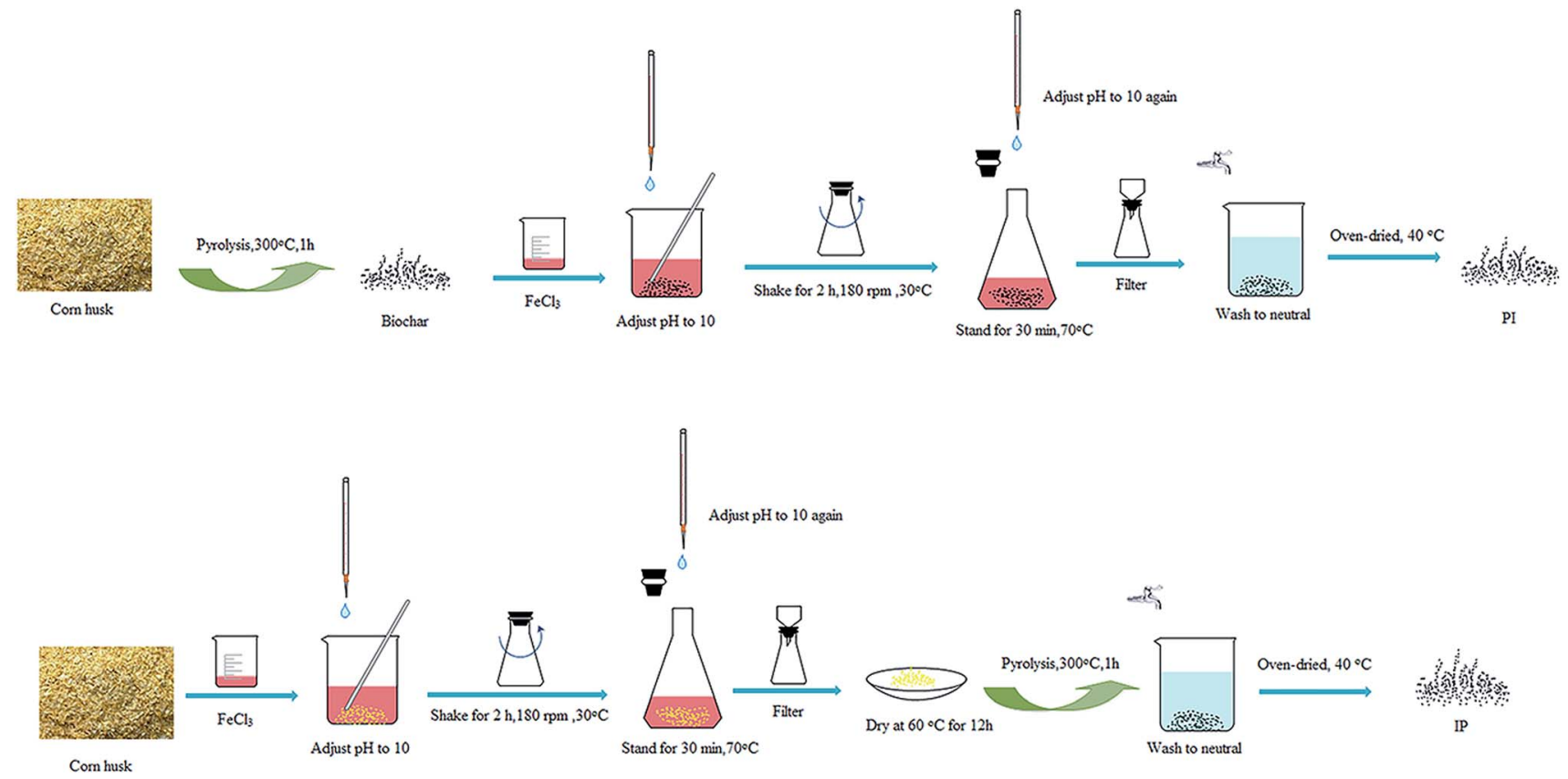

Fig. 2 Procedure for the preparation of PI and IP. 
D8 Advance) was utilized to character the components of Feloaded biochar. The samples were scanned in the range of 5$90{ }^{\circ} \mathrm{C}$ using $\mathrm{Cu}-\mathrm{K} \alpha$ radiation at $40 \mathrm{kV} .{ }^{\mathbf{1 2 , 1 4}}$ The modified-biochar was dissolved by nitric and hydrochloric acid, and the iron content was determined by Inductively Coupled Plasma-Atomic Emission Spectrometry (ICP-AES). The surface functional groups of sample were investigated by FTIR spectroscopy (Thermo Fisher Scientific, Nicolet-46). The powder sample was mixed with $\mathrm{KBr}$, then pressed into pellets with a radius of $0.65 \mathrm{~cm}$. The spectra were recorded in the mid-infrared from 4000 to $400 \mathrm{~cm}^{-1}$ with $4 \mathrm{~cm}^{-1}$ resolution. ${ }^{15-17}$

\subsection{Data analysis}

The amount of TC and LEV absorbed on Fe-loaded biochar could be calculated by the following formula.

$$
q_{\mathrm{e}}=\frac{\left(c_{0}-c_{\mathrm{e}}\right) \times V}{M}
$$

where $q_{\mathrm{e}}\left(\mathrm{mmol} \mathrm{g}^{-1}\right)$ is the equilibrium adsorption capacity; $c_{0}$ and $c_{\mathrm{e}}\left(\mathrm{mmol} \mathrm{L}^{-1}\right)$ are initial and equilibrium concentrations of antibiotic; $V(\mathrm{~L})$ is the volume of the solution; $M(\mathrm{~g})$ is the mass of adsorbent.

The pseudo-first-order kinetic model, the pseudo-secondorder kinetic model and intra-particle diffusion model were used to fit the kinetics data. The equations were written as follows.

$$
\begin{gathered}
q_{\mathrm{t}}=q_{\mathrm{e}}\left(1-\exp \left(-k_{1} t\right)\right) \\
q_{t}=\frac{q_{\mathrm{e}}{ }^{2} k_{2} t}{1+q_{\mathrm{e}} k_{2} t} \\
q_{t}=k_{\mathrm{i}} t^{0.5}+C
\end{gathered}
$$

where, $q_{t}$ and $q_{\mathrm{e}}\left(\mathrm{mmol} \mathrm{g}^{-1}\right)$ are the amount of antibiotics adsorbed at time $t(\mathrm{~h})$ and equilibrium; $k_{1}\left(\mathrm{~h}^{-1}\right)$ and $k_{2}(\mathrm{~g}$ $\mathrm{mmol}^{-1} \mathrm{~h}^{-1}$ ) are the observed rate constants of the pseudo-firstorder and pseudo-second-order, respectively; $k_{\mathrm{i}}\left(\mathrm{mmol} \mathrm{h}{ }^{0.5} \mathrm{~g}^{-1}\right)$ is intra-particle diffusion rate constant; $C$ is the intercept reflecting the extent of the boundary layer thickness. ${ }^{18}$

Freundlich, Langmuir and Temkin isotherm models were utilized to depict the adsorption performance.

$$
\begin{gathered}
q_{\mathrm{e}}=K_{\mathrm{F}} C_{\mathrm{e}}{ }^{1 / n} \\
q_{\mathrm{e}}=\frac{q_{\mathrm{m}} K_{\mathrm{L}} C_{\mathrm{e}}}{1+K_{\mathrm{L}} C_{\mathrm{e}}} \\
q_{\mathrm{e}}=\frac{R T}{b_{\mathrm{T}}} \ln \left(K_{\mathrm{T}} C_{\mathrm{e}}\right)
\end{gathered}
$$

where $K_{\mathrm{F}}\left(\mathrm{mmol}^{(1-1 / n)} \mathrm{L}^{1 / n} \mathrm{~g}^{-1}\right)$ is the Freundlich constant related to the adsorption capacity; $n$ is concerned with the adsorption intensity; $K_{\mathrm{L}}\left(\mathrm{L} \mathrm{mmol}^{-1}\right)$ represents the Langmuir coefficient correspond to the bonding force of adsorption; $q_{\mathrm{m}}$ $\left(\mathrm{mmol} \mathrm{g}^{-1}\right)$ is the maximum adsorption capacity; $K_{\mathrm{T}}\left(\mathrm{L} \mathrm{mmol}^{-1}\right)$ is equilibrium bond constant related to the maximum energy of bond; $b_{\mathrm{T}}$ is the Temkin isotherm constant; $R$ and $T$ are the universal gas constant and absolute temperature.
The difference between original adsorption amount and regenerated adsorption amount in different cycles can be calculated by the following formula.

$$
\text { Difference }(\%)=\frac{Q_{0}-Q_{n}}{Q_{0}} \times 100 \%
$$

where, $n$ is the number of cycles, $Q_{0}\left(\mathrm{mmol} \mathrm{g}^{-1}\right)$ is original amount, $Q_{n}\left(\mathrm{mmol} \mathrm{g}^{-1}\right)$ is adsorption amount in cycle $n$.

\section{Results and discussion}

\subsection{Characterization of biochar}

3.1.1 XRD. The XRD pattern (Fig. 3) of IP displayed the diffraction peaks at $30.6^{\circ}, 35.8^{\circ}, 43.4^{\circ}, 57.3^{\circ}, 63.1^{\circ}$, which was aligned with the standard XRD data of $\gamma-\mathrm{Fe}_{2} \mathrm{O}_{3},{ }^{19,20}$ coincided with (220), (311), (400), (511) and (440) planes, respectively. In contrast, as PI, there was only a broad band, attributed to amorphous hydrous iron oxide. ${ }^{21,22}$

\subsection{Effects of $\mathbf{p H}$}

Fig. 4 illustrated the antibiotics adsorption at different equilibrium $\mathrm{pH}$ values. In the PI system, the amount of TC
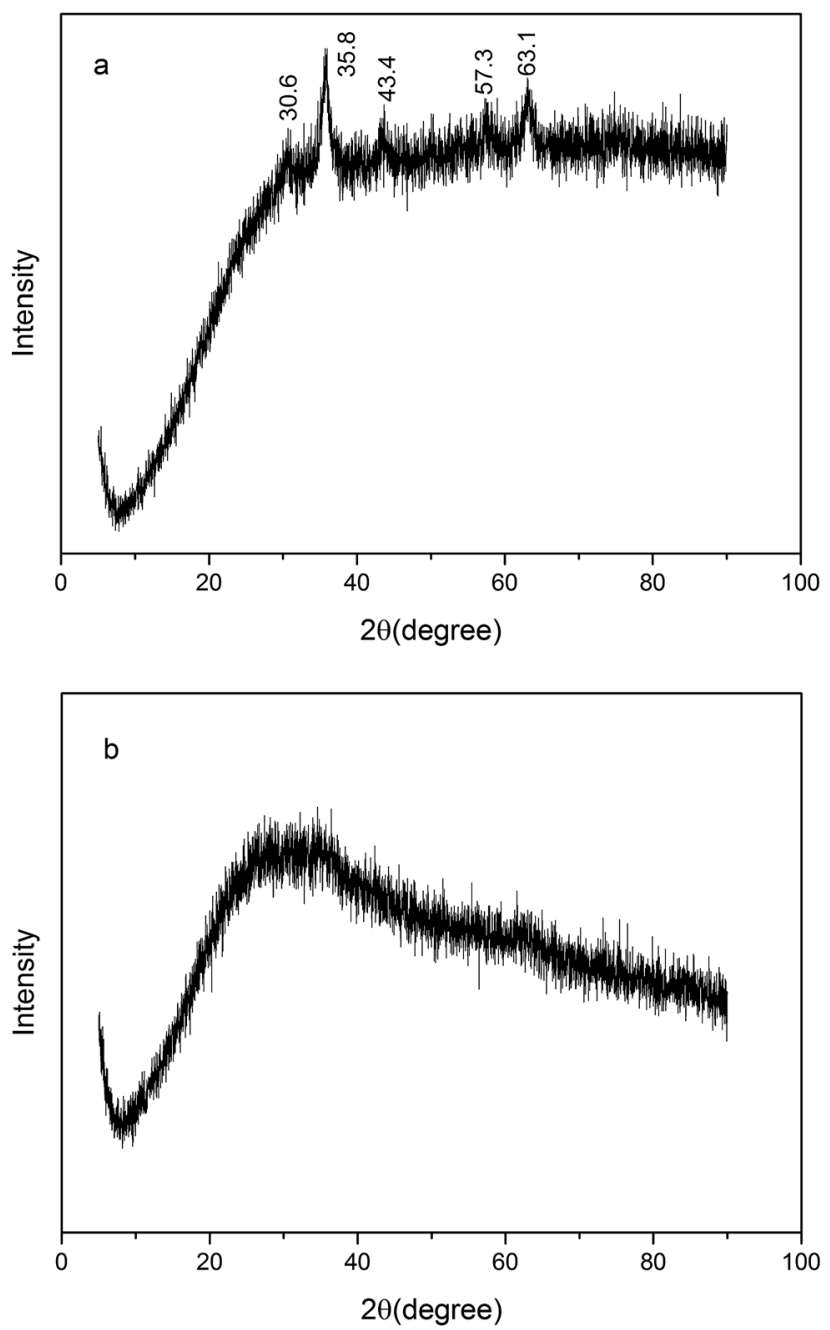

Fig. 3 XRD of IP (a) and PI (b). 


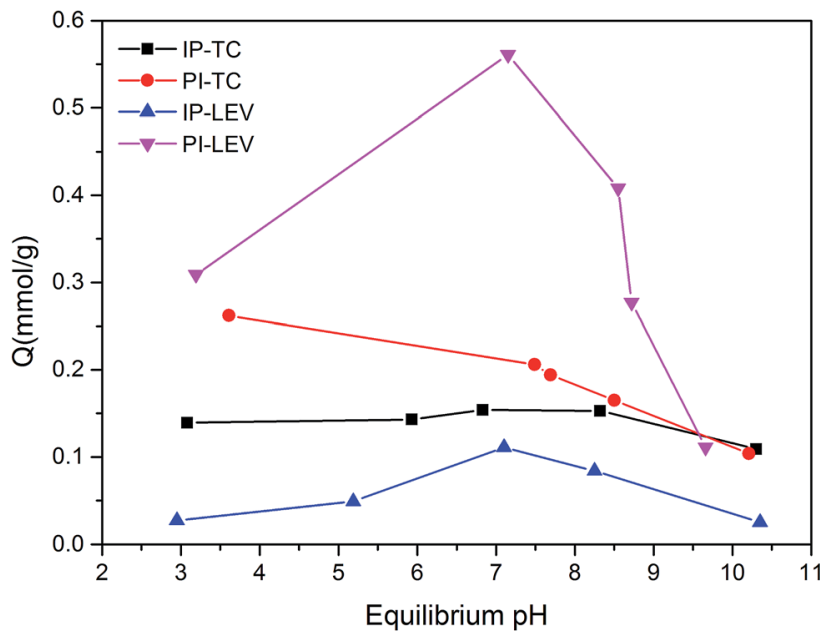

Fig. 4 Adsorption amounts at different $\mathrm{pH}$ values.

adsorption decreased as $\mathrm{pH}$ increased. Because the $\mathrm{pH}_{\mathrm{pzc}}$ was lower than 2.5, PI surface was negatively charged during the whole experiment. While TC existed as a cationic under lower $\mathrm{pH}$, which was easy to combine with the negative sites on the PI surface. ${ }^{23}$ When $\mathrm{pH}$ increased, TC transformed into an anion, at which time the electrostatic repulsion enhanced, and the adsorption capacity reduced. Compared with PI, the IP adsorption capacity was much lower, especially under acid condition. This may due to the limitation of the active adsorption sites on IP.

For LEV, the optimal adsorption capacity appeared at around the neutral condition in both the PI and IP adsorption systems. This was probably related to synthetical effect of the deprotonated carboxyl group, which was favorable for the complexation with ferric oxide ${ }^{24}$ and the electrostatic repulsion also. Under acidic conditions, the percentage of deprotonated carboxyl group declined, resulting in the reduced adsorption amount. During alkaline conditions, electrostatic repulsion inhibited the contact of LEV molecule with biochar, leading to the adsorption decrement.

Although PI $\left(24.9 \%, 94.9 \mathrm{~m}^{2} \mathrm{~g}^{-1}\right)$ contained lower Fe content and surface area than IP $\left(54.10 \%, 112.45 \mathrm{~m}^{2} \mathrm{~g}^{-1}\right)$, it showed a larger adsorption capacity for both TC and LEV. This implied that the Fe and surface area were not the main adsorption active sites. So other functional group may play a key role during the adsorption.

\subsection{Adsorption kinetics}

Adsorption kinetic was a widely used method to explore the adsorption rate. The results of the relevant parameters were listed in the Table 1. It could be seen that the pseudo-secondorder model were more accurate than the pseudo-first-order model for all adsorptions, which suggested that the antibiotics adsorption on PI or IP was mainly controlled by chemical process. ${ }^{25}$ Intra-particle diffusion model described the IP removal results well, which indicated that intra-particle was the main control steps during adsorption of two antibiotics on IP..$^{26,27}$

\subsection{Adsorption isotherms}

The adsorption isotherm could explain the functional relationship between adsorption capacity and concentration. Table 2 listed the fitting results of two isotherm models. The $q_{\max }$ values of PI were $0.310 \mathrm{mmol} \mathrm{g}^{-1}\left(149.1 \mathrm{mg} \mathrm{g}^{-1}\right)$ for TC and $0.757 \mathrm{mmol} \mathrm{g}^{-1}\left(273.7 \mathrm{mg} \mathrm{g}^{-1}\right)$ for LEV respectively. Both were

Table 1 The parameters for the kinetic models of TC and LEV adsorbed to modified biochars

\begin{tabular}{|c|c|c|c|c|c|}
\hline \multirow[t]{2}{*}{ Pseudo-first-order } & $q_{\mathrm{e}}\left(\mathrm{mmol} \mathrm{g}^{-1}\right)$ & 0.0964 & 0.1572 & 0.5451 & 0.2494 \\
\hline & $k_{1}\left(\mathrm{~h}^{-1}\right)$ & 0.2081 & 0.1613 & 5.576 & 2.822 \\
\hline \multirow[t]{3}{*}{ Pseudo-second-order } & $q_{\mathrm{e}}\left(\mathrm{mmol} \mathrm{g}^{-1}\right)$ & 0.1119 & 0.1948 & 0.5686 & 0.2620 \\
\hline & $k_{2}\left(\mathrm{~g}(\mathrm{mmol} \mathrm{h})^{-1}\right)$ & 2.439 & 0.870 & 15.878 & 15.50 \\
\hline & $R^{2}$ & 0.90417 & 0.9909 & 0.9577 & 0.9175 \\
\hline & $R^{2}$ & 0.9871 & 0.9926 & 0.5687 & 0.8254 \\
\hline
\end{tabular}

Table 2 The fitting parameters for the isotherm models of TC and LEV adsorbed to modified biochars

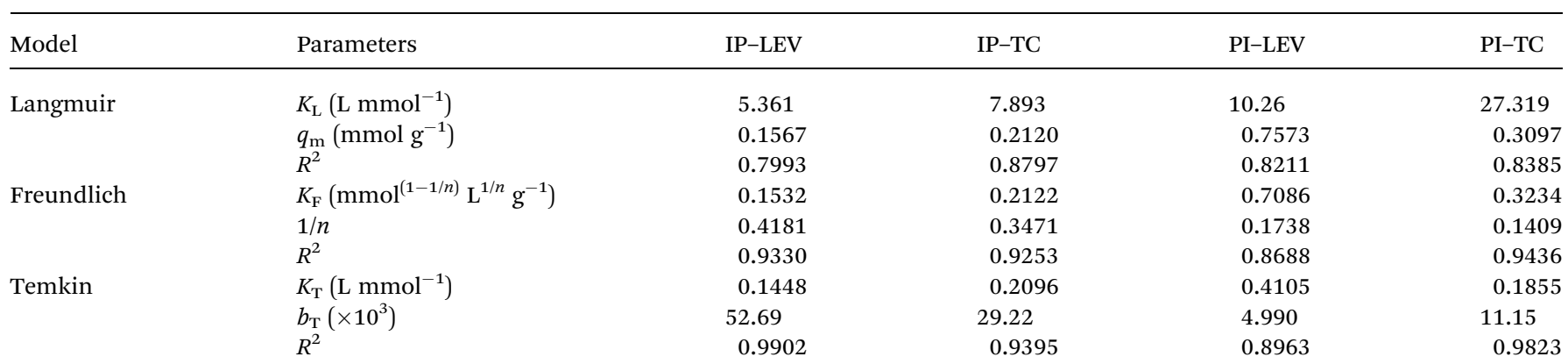


much higher than those of IP. In addition, compared with some other adsorbents (Table 3), PI and IP also showed the outstanding adsorption capacity.

Freundlich model was more appropriate for the TC and LEV adsorption behaviors on the two adsorbents, indicating that the adsorption took place on heterogeneous surface, which was probably due to the different kinds of active sites. ${ }^{6}$ The $n$ values were all greater than 2, indicating the strong interaction between the antibiotics and the modified biochars. ${ }^{34}$ In addition, the difference of LEV adsorption capacity between PI and IP was much more significant than that of TC. The Temkin isotherm model fitted the adsorption data better. This result indicated that electrostatic interaction had an effect on the interaction between modified-biochar and the two antibiotics. $^{35,36}$

\subsection{Adsorption mechanism}

3.5.1 XPS. The XPS spectra of O1s were summarized in Table 4. For IP, deconvolution of O1s spectra produced two peaks located at $530.1 \mathrm{eV}$ and $531.4 \mathrm{eV}$, corresponding to lattice$\mathrm{O}^{2-}$ and $-\mathrm{OH}_{\text {lat }} / \mathrm{C}-\mathrm{O} .^{37,38}$ After TC and LEV adsorption, the ratio of $-\mathrm{OH}_{\text {lat }}$ decreased from $34.38 \%$ to $27.52 \%$ and $26.62 \%$, respectively. It indicated that the $-\mathrm{OH}_{\text {lat }}$ was one of the functional groups in the adsorption process. For IP-TC, a new peak appeared at $532.8 \mathrm{eV}$, which were probably concerned with $\mathrm{C}-\mathrm{O}$ from TC. ${ }^{39}$ Also, a new peak at $533.0 \mathrm{eV}$ appeared for PI-LEV that was likely ascribed to the $\mathrm{O}=\mathrm{C}-\mathrm{O}$ or $\mathrm{C}-\mathrm{O}$ from $\mathrm{LEV}$. Moreover, as can be seen from Table 5, deconvolved N1s of TC into two peaks at $399.4 \mathrm{eV}$ and $401.7 \mathrm{eV}$ were assigned to $-\mathrm{NH}-$ or $-\mathrm{NH}_{2}$ and $\mathrm{C}-\mathrm{N}-\mathrm{C} .^{\mathbf{6}, 40}$ After adsorption, the binding energy shifted upward to $399.8 \mathrm{eV}$ and $403.2 \mathrm{eV}$, respectively, due to the

Table 3 Adsorption capacities of TC and LEV by different adsorbents

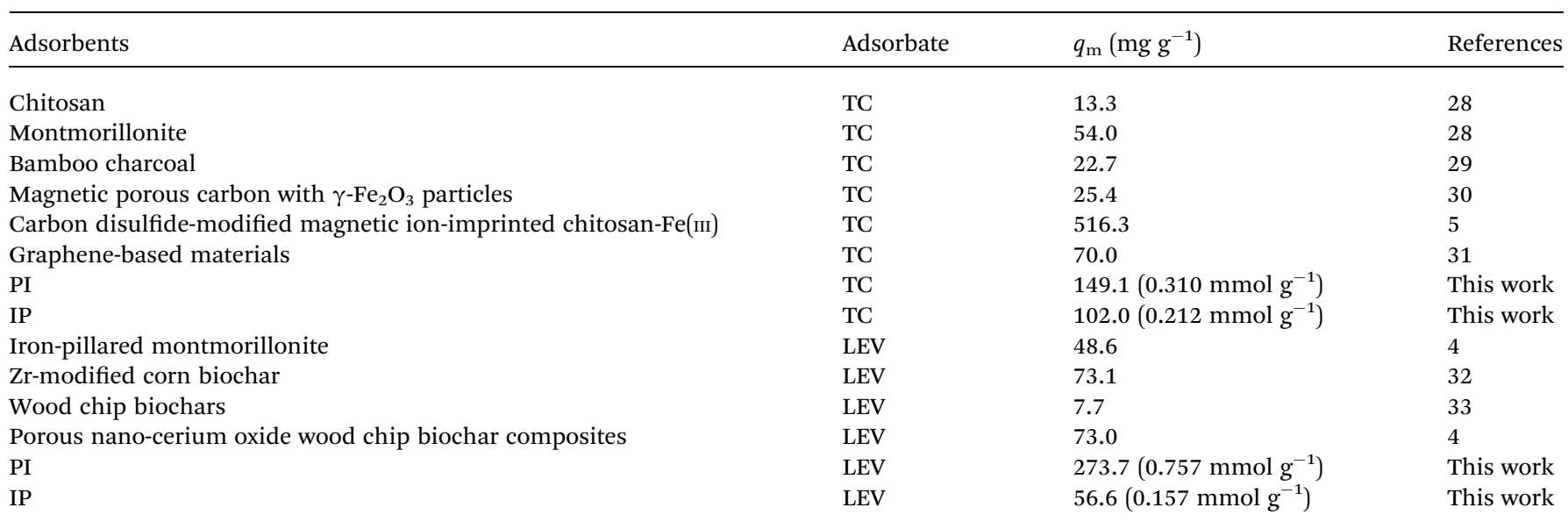

Table 4 Peak positions and areas of O1s before and after adsorption by IP and PI

\begin{tabular}{|c|c|c|c|}
\hline IP & 530.1 & Lattice-O ${ }^{2-}$ & 65.62 \\
\hline \multirow[t]{3}{*}{ IP-TC } & 530.1 & Lattice- $^{2-}$ & 62.22 \\
\hline & 531.4 & $-\mathrm{OH}_{\mathrm{lat}} /-\mathrm{OH}$ from TC & 27.52 \\
\hline & 532.8 & $\mathrm{C}-\mathrm{O}$ from $\mathrm{TC}$ & 10.26 \\
\hline & 533.0 & $\mathrm{O}=\mathrm{C}-\mathrm{O} / \mathrm{C}-\mathrm{O}$ from LEV & 5.830 \\
\hline \multirow[t]{4}{*}{ PI } & 530.1 & Lattice- $\mathrm{O}^{2-}$ & 6.442 \\
\hline & 531.1 & $-\mathrm{OH}_{\text {lat }}$ & 7.372 \\
\hline & 532.3 & $-\mathrm{OH}_{\mathrm{ads}}$ & 58.65 \\
\hline & 533.6 & $\mathrm{H}_{2} \mathrm{O}$ & 27.54 \\
\hline PI-TC & 530.2 & Lattice-O $^{2-}$ & 8.755 \\
\hline & 531.2 & $-\mathrm{OH}_{\text {lat }} /-\mathrm{OH}$ from LEV & 18.94 \\
\hline & 532.2 & $-\mathrm{OH}_{\mathrm{ads}}$ & 44.69 \\
\hline & 533.5 & $\mathrm{H}_{2} \mathrm{O}$ & 27.36 \\
\hline
\end{tabular}


Table 5 XPS peak positions of samples

\begin{tabular}{lll}
\hline Element & Sample & Binding energy $(\mathrm{eV})$ \\
\hline $\mathrm{F}$ & LEV & 686.7 \\
& IP-LEV & 687.3 \\
$\mathrm{~N}$ & PI-LEV & 687.2 \\
& TC & $399.4,401.7$ \\
& IP-TC & $399.8,403.2$ \\
& PI-TC & $399.9,402.8$
\end{tabular}

protonated amines or the formation of hydrogen bonds. ${ }^{41,42}$ The F1s signal of LEV presented at $686.7 \mathrm{eV}$ and was transferred to $687.3 \mathrm{eV}$ after adsorption. The increase in binding energy may be attributed to the replacement of $-\mathrm{OH}$ and the interaction between metal and $\mathrm{F}^{\mathbf{4 3}}$

As for the PI, the O1s were divided into three peaks, $-\mathrm{OH}_{\text {lat }}$, $-\mathrm{OH}_{\mathrm{ads}}$, and adsorbed $\mathrm{H}_{2} \mathrm{O}$. Compared with the IP, the lattice$\mathrm{O}^{2-}$ and the $-\mathrm{OH}_{\text {lat }}$ portions on PI were much lower. PI contained a large amount of $-\mathrm{OH}_{\mathrm{ads}}$. Previous studies had also stated that amorphous materials could offer more (or higher density) hydroxyl groups. ${ }^{44}$ The $-\mathrm{OH}_{\text {ads }}$ content reduced from $58.65 \%$ to $43.41 \%$ and $44.69 \%$ after TC and LEV adsorption, which indicated the key role of $-\mathrm{OH}_{\text {ads }}$ in the adsorption. The $-\mathrm{OH}_{\text {lat }}$ was also thought to be one of the adsorption functional groups despite its percentage increase after adsorption, on account of overlap of the $-\mathrm{OH}$ from LEV or TC. Similarly as IP, the F and N binding energy values of PI both increased after adsorption.

3.5.2 FTIR. In the FTIR spectra of IP (Fig. 5), for both IP and PI, the bands between $3600-3700 \mathrm{~cm}^{-1}$ were concerned with terminal-bonded hydroxyl group. ${ }^{45}$ The wavenumber at $3407 \mathrm{~cm}^{-1}$ referred to the stretching vibration of hydroxyl, including the lattice $-\mathrm{OH}\left(-\mathrm{OH}_{\mathrm{lat}}\right)$ and adsorbed $-\mathrm{OH}$ $\left(-\mathrm{OH}_{\mathrm{ads}}\right){ }^{46,47}$ By contrast, the $-\mathrm{OH}$ peak of PI at $3400 \mathrm{~cm}^{-1}$ was broader. It could be found that the peaks between 3600$3700 \mathrm{~cm}^{-1}$ in PI and IP all disappeared after adsorption due to the reactions between terminal $-\mathrm{OH}$ and LEV or TC molecular. Furthermore, the $-\mathrm{OH}$ stretching vibrations at around $3400 \mathrm{~cm}^{-1}$ all changed after adsorption, shifting upward or downward. It might be attributable to the synthetical results of inductive effects, complexation, hydrogen bonding, protonation and the overlap of amino group peak. ${ }^{48-51}$

Additionally, the frequency at $1291 \mathrm{~cm}^{-1}$ (Fig. 5c), assigned to the coupling of carboxylic acid $\mathrm{C}-\mathrm{O}$ stretching and $\mathrm{O}-\mathrm{H}$ deformation, changed to $1273 \mathrm{~cm}^{-1}$ (Fig. 5b), because Fe combined with the $\mathrm{O}$ atom of carboxyl. This could be confirmed by the shift of Fe-O stretching peak after LEV adsorption. The peak at $1621 \mathrm{~cm}^{-1}$ (Fig. 5c), representing the $\mathrm{C}=\mathrm{O}$ in LEV molecular, transferred to $1522 \mathrm{~cm}^{-1}$ (Fig. 5b) after adsorption, illustrating that $\mathrm{C}=\mathrm{O}$ was involved in the reaction. In addition, the bands in PI-LEV at $1624 \mathrm{~cm}^{-1}$ and $1384 \mathrm{~cm}^{-1}$ corresponded to the antisymmetric and symmetric stretching vibrations of the carboxylate group. ${ }^{52,53}$ And the $\Delta \nu$ value was $240 \mathrm{~cm}^{-1}$. It was comparable to the free LEV $\left(\Delta \nu_{\text {free }}\right)$, which was $245 \mathrm{~cm}^{-1}$, implying that the complex was the bridging-type. ${ }^{54,55}$ As for the PI-LEV FTIR spectra, the changes were very similar as the above.

For the TC spectra (Fig. 5c), the $1670 \mathrm{~cm}^{-1}$ bands were ascribed to the carbonyl of the amide in ring A of TC. The frequencies at $1616 \mathrm{~cm}^{-1}$ and $1582 \mathrm{~cm}^{-1}$ corresponded to the carbonyl groups in A and $\mathrm{C}$ rings, respectively. After adsorption on IP, the two peaks vanished (Fig. 5b). The FTIR spectrum of
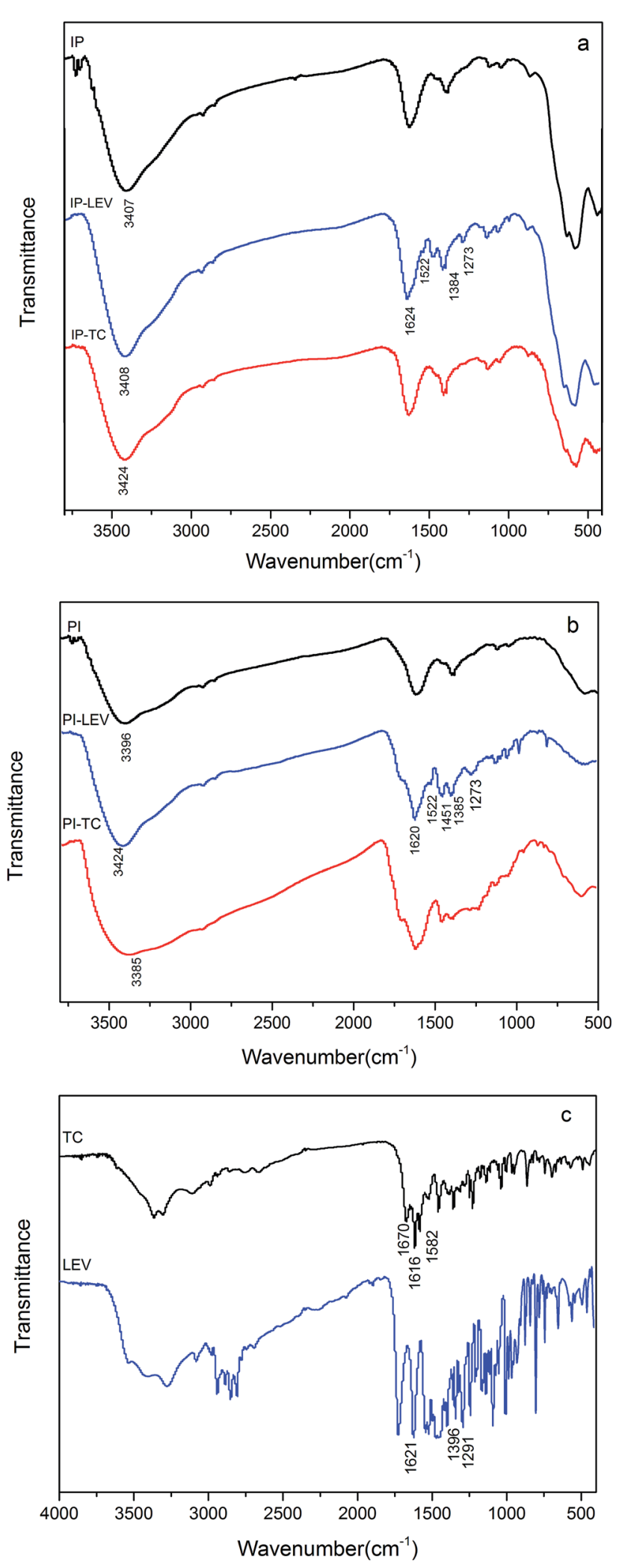

Fig. 5 FT-IR spectra of IP (a), PI (b) before and after adsorption, FT-IR spectra of LEV and TC (c). 
PI-TC was similar as the above. This phenomenon revealed that interaction between carbonyl (C-1 : C-3 in ring A, C-11 in ring $\mathrm{C}$, amide group in ring A) and $\mathrm{Fe}^{6}$

3.5.3 Adsorption performance comparison and competitive adsorption. As can be seen from Fig. 4, obviously, PI could adsorb more antibiotics, which indicated that PI had more active adsorption sites, including the $-\mathrm{OH}$ group as mentioned before. PI owned a higher portion of - $\mathrm{OH}$, and correspondingly, LEV adsorption capacity was more than 4 times higher than that of IP. So, it was quite possible that $-\mathrm{OH}$ played the main role in the LEV adsorption.

To understand the adsorption behavior and mechanism further, competitive adsorption was investigated (Fig. 6). In the PI binary adsorption systems, LEV maintained the high adsorption capacity or only decreased slightly. It could be deduced that $-\mathrm{OH}$ would give priority to LEV molecular for combination rather than TC. On the other hand, TC decreased significantly in the presence of LEV, but it still remained some adsorption, demonstrating that $-\mathrm{OH}$ was not the only or not the most important reason for TC adsorption. Moreover, in the IP binary adsorption systems, LEV's priority was not so obvious due to less $-\mathrm{OH}$ in IP.
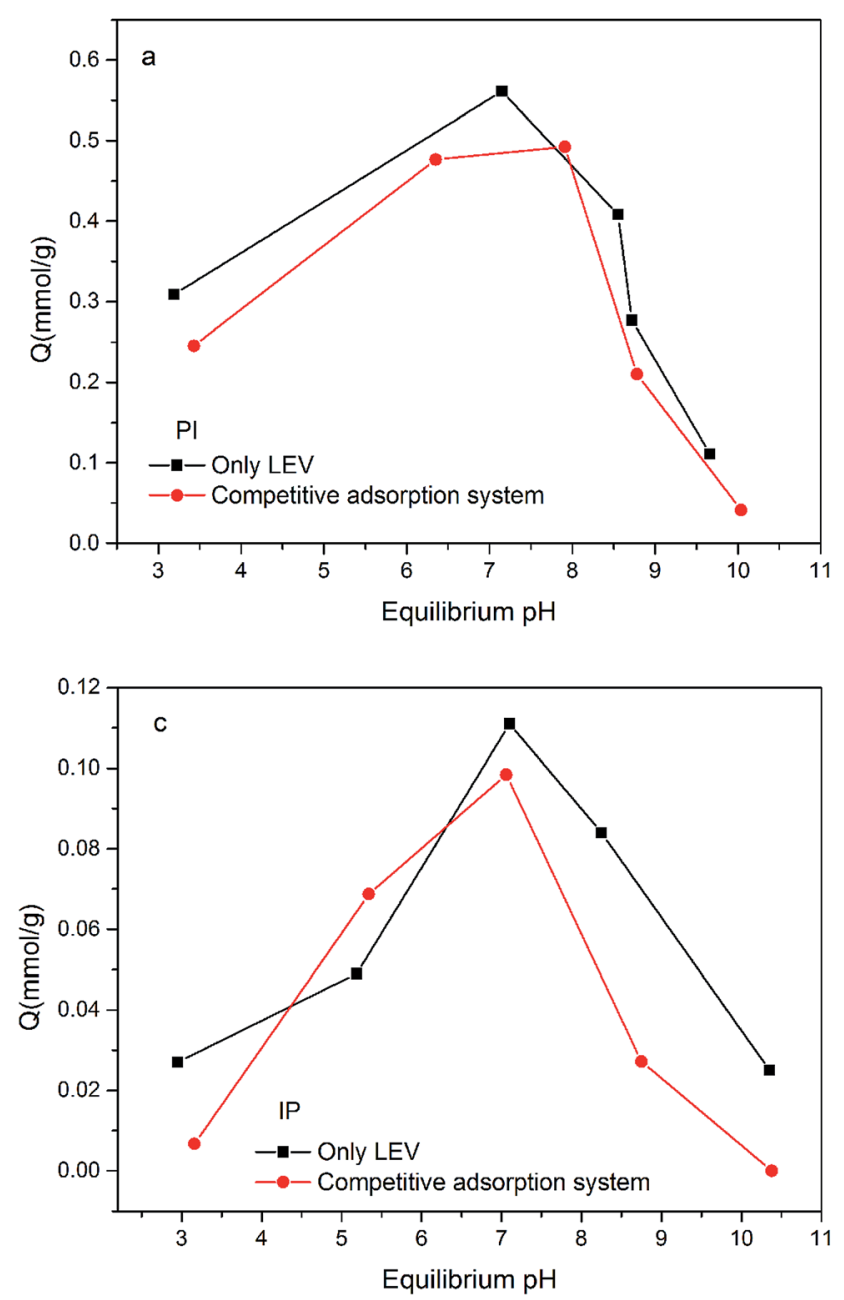

3.5.4 Possible adsorption mechanisms. In summary, from the analysis above, the mechanisms of LEV adsorption may include bridging bidentate complexation, hydrogen bonding, F-replacement and electrostatic attraction. The first three mechanisms were all closely related to the $-\mathrm{OH}$ groups. The adsorption of TC was due to interaction between carbonyl and $\mathrm{Fe}$, hydrogen bonding and electrostatic attraction. The adsorption mechanisms were schematically depicted in Fig. 7.

PI with amorphous ferric oxide could provide more $-\mathrm{OH}$ groups, mainly in the form of $-\mathrm{OH}_{\mathrm{ads}}$, enhancing both the LEV and TC adsorption capacities. $-\mathrm{OH}$ groups preferred to combine with LEV molecular rather than TC. And it played the leading role in LEV adsorption, however it was not the only or not the most important reason for TC adsorption, especially at the nearneutral condition.

\subsection{Regeneration and reuse analysis}

Fig. 8 showed the results in five adsorption cycles. Compared with the adsorption capacity in the first cycle, except for PI-LEV, other adsorption amounts were maintained high and stable.
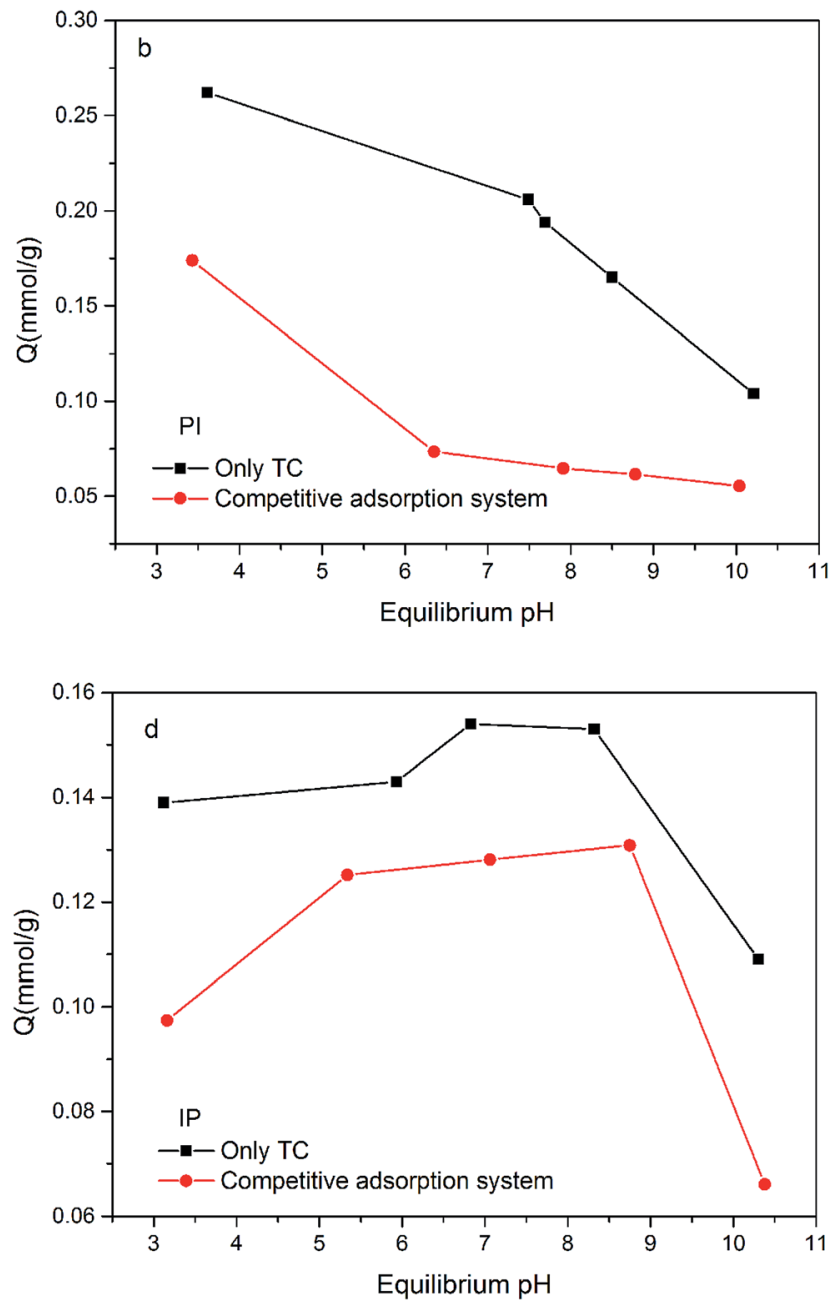

Fig. 6 The adsorption amount in the single and competitive systems: (a) LEV adsorption amount by Pl; (b) TC adsorption amount by Pl; (c) LEV adsorption amount by IP; (d) TC adsorption amount by IP. 
a<smiles>CC1COc2c(N3CCN(C)CC3)c(F)cc3c(=O)ccn1c23</smiles><smiles>CC1COc2c(N3CCNCC3)c(F)cc3c(=O)c(C(=O)O)cn1c23</smiles>

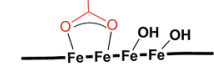
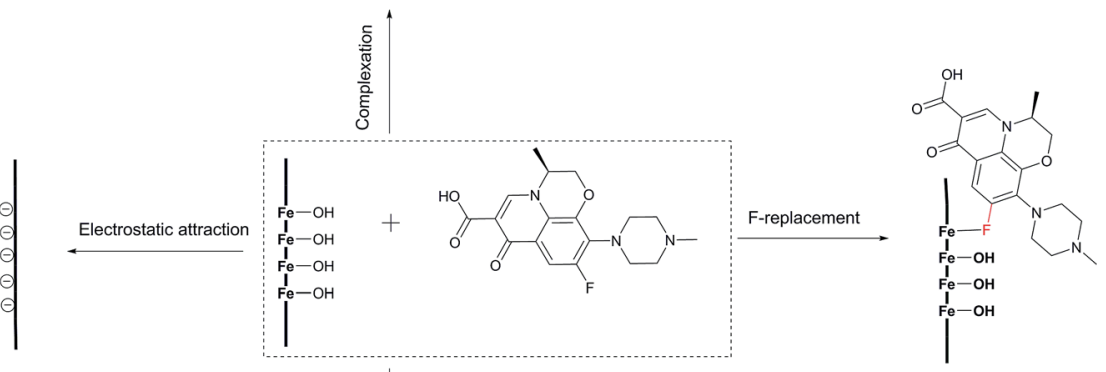

b
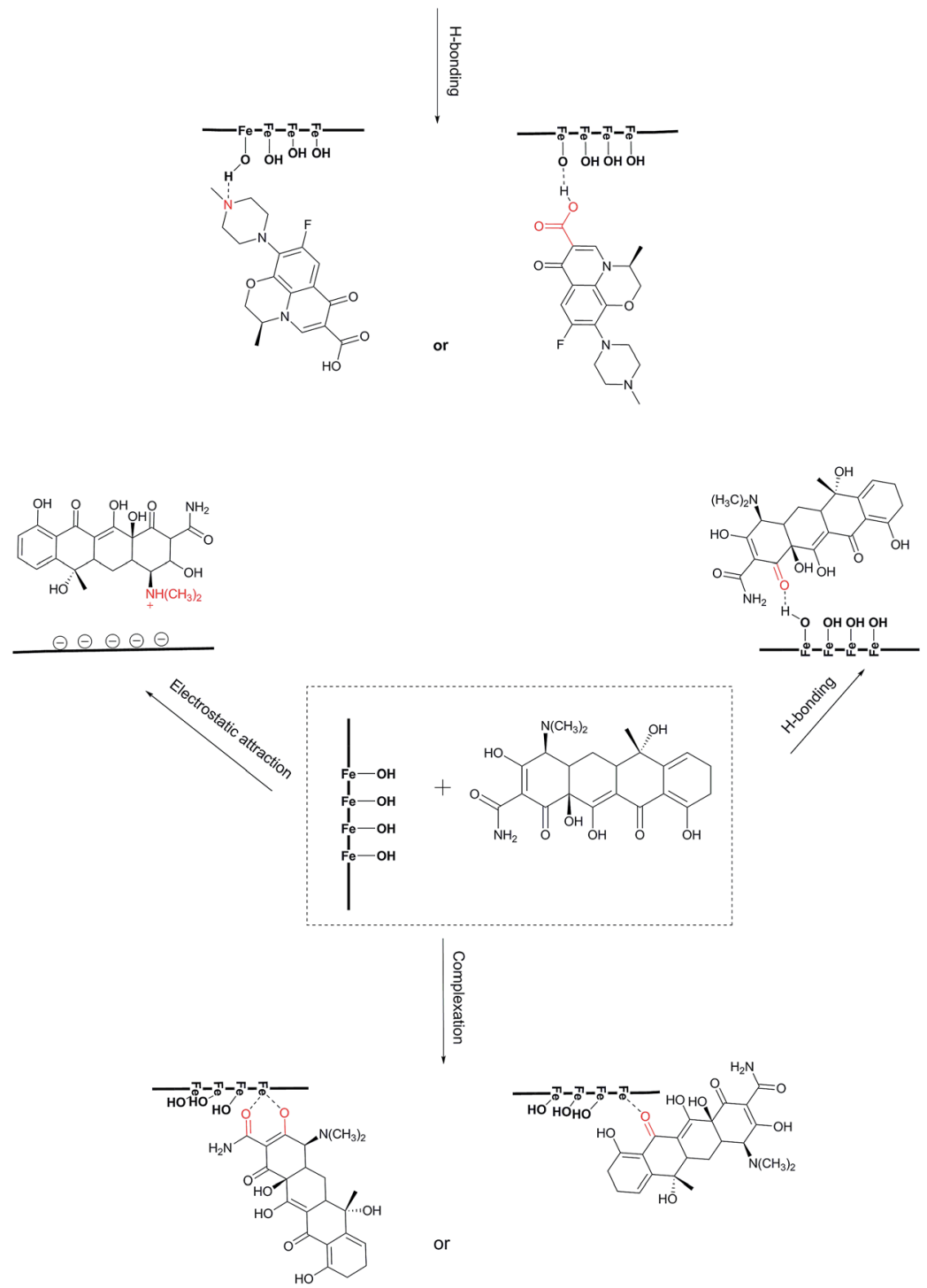

Fig. 7 Possible adsorption mechanisms for LEV (a) and TC (b).

Compared with the original adsorption amount, the differences were less than $\pm 20 \%$ in the reuse cycle experiments. The adsorption amount of PI-LEV decreased, but it can also be kept more than $64 \%$ of the original adsorption amount. This phenomenon manifested that the IP and PI could be reused and recycled efficiently. 


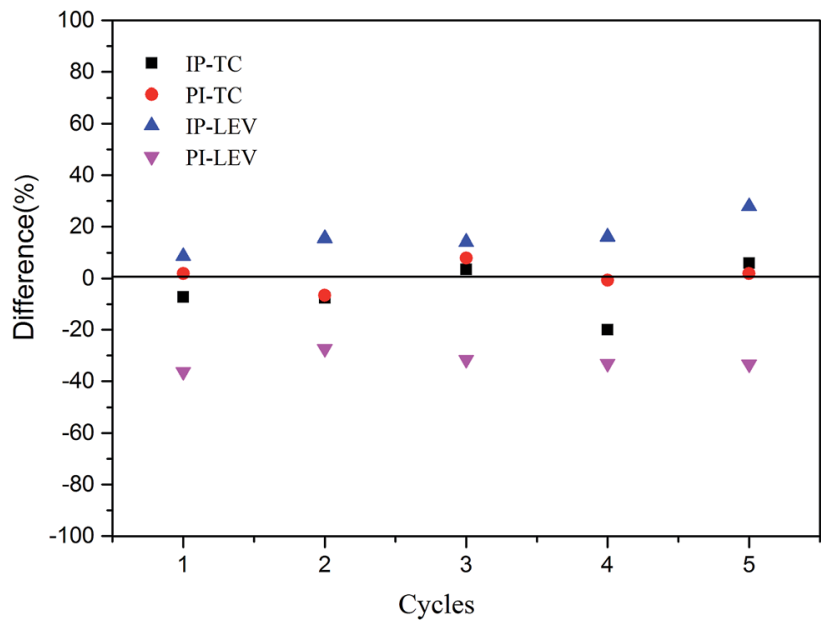

Fig. 8 Reuse experiment results.

\section{Conclusions}

In this study, an agricultural waste, corn husk, was used as carrier to prepare adsorbents with two different forms of iron oxides. IP biochar showed lower adsorption capacity. PI, mainly covered with amorphous hydrated iron oxide, could provide more $-\mathrm{OH}$, especially $-\mathrm{OH}_{\text {ads }}$, as the reactive sites. Moreover, -OH was inclined to integrate with LEV in comparison with TC. FT-IR and XPS results indicated that the mechanisms of LEV adsorption were the hydrogen bonding, F-replacement, electrostatic attraction and bridging bidentate complexation. TC adsorption may involve complexation, hydrogen bonding, electrostatic attraction.

\section{Conflicts of interest}

There are no conflicts to declare.

\section{Acknowledgements}

This research was supported by the Fundamental Research Funds for the Central Universities (2632019FY02), the Jiangsu Overseas Visiting Scholar Program for University Prominent Young \& Middle-aged Teachers and Presidents, the Qing Lan Project, Natural Science Foundation of Jiangsu Province (BK20160744), National Natural Science Foundation of China (21707166) and the College Students Innovation Project for the R\&D of Novel Drugs (J1310032).

\section{References}

1 I. Sousa, V. Claro, J. L. Pereira, A. L. Amaral, S. L. Cunha, B. Castro, M. J. Feio, E. Pereira and P. Gameiro, Synthesis, characterization and antibacterial studies of a copper (II) levofloxacin ternary complex, J. Inorg. Nucl. Chem., 2012, 110, 64.

2 D. J. Margolis, M. Fanelli, O. Hoffstad and J. D. Lewis, Potential association between the oral tetracycline class of antimicrobials used to treat acne and inflammatory bowel disease, Am. J. Gastroenterol., 2010, 105, 2610.

3 Y. Y. Zhou, X. C. Liu, Y. J. Xiang and L. Tang, Modification of biochar derived from sawdust and its application in removal of tetracycline and copper from aqueous solution: Adsorption mechanism and modelling, Bioresour. Technol., 2017, 245, 266.

4 Y. N. Liu, C. X. Dong, H. Wei, W. H. Yuan and K. B. Li, Adsorption of levofloxacin onto an iron-pillared montmorillonite (clay mineral): kinetics, equilibrium and mechanism, Appl. Clay Sci., 2015, 118, 301.

5 A. W. Chen, C. Shang, J. H. Shao, Y. Q. Lin, S. Luo, J. C. Zhang, H. L. Huang, M. Lei and Q. R. Zeng, Carbon disulfide-modified magnetic ion-imprinted chitosan-Fe(III): A novel adsorbent for simultaneous removal of tetracycline and cadmium, Carbohydr. Polym., 2017, 155, 19.

6 Z. Y. Zhang, H. J. Liu, L. Y. Wu, H. C. Lan and J. H. Qu, Preparation of amino-Fe(III) functionalized mesoporous silica for synergistic adsorption of tetracycline and copper, Chemosphere, 2015, 138, 625.

7 A. Vazquez, D. B. H. Uresti and S. Obregon, Electrophoretic deposition of CdS coatings and their photocatalytic activities in the degradation of tetracycline antibiotic, Appl. Surf. Sci., 2016, 386, 412.

8 J. H. Li, M. S. Han, Y. Guo, F. Wang, L. J. Meng, D. J. Mao, S. S. Ding and C. Sun, Hydrothermal synthesis of novel flower-like BiVO4/Bi2Ti2O7 with superior photocatalytic activity toward tetracycline removal, Appl. Catal., A, 2016, 524, 105.

9 M. F. Nazar, W. Azeem, U. A. Rana, M. Ashfaq, A. Lashin, N. Arifi, H. M. A. U. Rahman, A. M. Lazim and A. Mahmood, pH-dependent probing of levofloxacin assimilated in surfactant mediated assemblies: Insights from photoluminescent and chromatographic measurements, J. Mol. Liq., 2016, 220, 26.

10 Z. L. Song, Y. J. Ma, G. G. Xia, Y. Wang, W. Kapadia, Z. Y. Sun, W. Wu, H. C. Gu, W. G. Cui and X. Y. Huang, In vitro and in vivo combined antibacterial effect of levofloxacin/silver coloaded electrospun fibrous membranes, J. Mater. Chem. B, 2017, 5, 7632.

11 K. S. Walton and R. Q. Snurr, Applicability of the BET Method for Determining Surface Areas of Microporous Metal-Organic Frameworks, J. Am. Chem. Soc., 2007, 27, 8552.

12 H. W. Wei, Q. Y. Feng, H. Yang, E. Alam, B. Gao and D. Gu, Modified biochar supported Ag/Fe nanoparticles used for removal of cephalexin in solution: Characterization, kinetics and mechanisms, Colloids Surf., A, 2017, 517, 63.

13 Y. Yuan, T. Yuan, D. M. Wang, J. H. Tang and S. G. Zhou, Sewage sludge biochar as an efficient catalyst for oxygen reduction reaction in an microbial fuel cell, Bioresour. Technol., 2013, 144, 115.

14 Z. H. Ruan, J. H. Wu, J. F. Huang, Z. T. Lin, Y. F. Li, Y. L. Liu, P. Y. Cao, Y. P. Fang, J. Xie and G. B. Jiang, Facile preparation of rosin-based biochar coated bentonite for supporting $\alpha$ $\mathrm{Fe}_{2} \mathrm{O}_{3}$ nanoparticles and its application for $\mathrm{Cr}(\mathrm{VI})$ adsorption, J. Mater. Chem. A, 2015, 3, 4595. 
15 S. Kloss, F. Zehetner, A. Dellantonio, R. Hamid, F. Ottner, V. Liedtke, M. Schwanninger, M. H. Gerzabek and G. Soja, Characterization of Slow Pyrolysis Biochars: Effects of Feedstocks and Pyrolysis Temperature on Biochar Properties, J. Environ. Qual., 2012, 41, 990.

16 B. M. Richveisova, V. Fristak, M. Pipiska, L. Duriska, E. M. Jimenez and G. Soja, Iron-impregnated biochars as effective phosphate sorption materials, Environ. Sci. Pollut. Res., 2017, 24, 463.

17 X. Hu, Z. H. Ding, A. R. Zimmerman, S. S. Wang and B. Gao, Batch and column sorption of arsenic onto ironimpregnated biochar synthesized through hydrolysis, Water Res., 2015, 68, 206.

18 H. Wang, C. R. Fang, Q. Wang, Y. X. Chu, Y. L. Song, Y. M. Chen and X. D. Xue, Sorption of tetracycline on biochar derived from rice straw and swine manure, $R S C$ Adv., 2018, 8, 16260.

19 S. S. Wang, B. Gao, A. R. Zimmerman, Y. C. Li, L. N. Ma, W. G. Harris and K. W. Migliaccioac, Removal of arsenic by magnetic biochar prepared from pinewood and natural hematit, Bioresour. Technol., 2015, 175, 391.

20 M. Zhang, B. Gao, S. Varnoosfaderani, A. Hebard, Y. Yao and M. Inyang, Preparation and characterization of a novel magnetic biochar for arsenic removal, Bioresour. Technol, 2013, 130, 457.

21 L. Han, S. Xue, S. C. Zhao, J. C. Yan, L. B. Qian, M. F. Chen and M. S. Yao, Biochar supported nanoscale iron particles for the efficient removal of methyl orange dye in queous solutions, PLoS One, 2015, 10, e0132067.

22 H. G. Zhou, Z. M. Jiang and S. Q. Wei, A novel absorbent of nano-Fe loaded biomass char and its enhanced adsorption capacity for phosphate in water, J. Chem., 2013, 2013, 1.

23 G. Caminati and M. Puggelli, Europium in phospholipid nanoscaffolds for the photophysical detection of antibiotic traces in solution, ResearchGate, 2011, vol. 6, p. 203.

$24 \mathrm{H}$. Wei, D. Hu, J. Su and K. B. Li, Intensification of levofloxacin sono-degradation in a $\mathrm{US} / \mathrm{H}_{2} \mathrm{O}_{2}$ system with $\mathrm{Fe}_{3} \mathrm{O}_{4}$ magnetic nanoparticles, Chin. J. Chem. Eng., 2015, 23, 296.

25 B. H. Huang, Y. G. Liu, B. Li, S. B. Liu, G. M. Zeng, Z. W. Zeng, X. H. Wang, Q. M. Ning, B. H. Zheng and C. P. Yang, Effect of $\mathrm{Cu}(\mathrm{II})$ ions on the enhancement of tetracycline adsorption by $\mathrm{Fe}_{3} \mathrm{O}_{4} @ \mathrm{SiO}_{2}$-Chitosan/graphene oxide nanocomposite, Carbohydr. Polym., 2017, 157, 576.

26 S. S. Fan, Y. Wang, Z. Wang, J. Tang, J. Tang and X. D. Li, Removal of methylene blue from aqueous solution by sewage sludge-derived biochar: Adsorption kinetics, equilibrium, thermodynamics and mechanism, J. Environ. Chem. Eng., 2017, 5, 601.

27 F. M. Pellera, A. Giannis, D. Kalderis, K. Anastasiadou, R. Stegmann, J. Y. Wang and E. Gidarakos, Adsorption of $\mathrm{Cu}(\mathrm{II})$ ions from aqueous solutions on biochars prepared from agricultural by-products, J. Environ. Manage., 2012, 96, 35.

28 L. Peng, Y. Q. Ren, J. D. Gu, P. F. Qin, Q. R. Zeng, J. H. Shao, M. Lei and L. Y. Chai, Iron improving bio-char derived from microalgae on removal of tetracycline from aqueous system, Environ. Sci. Pollut. Res., 2014, 21, 7631.

29 B. Kakavandia, A. Takdastana, N. Jaafarzadeh, M. Azizi, A. Mirzaei and A. Azari, Application of $\mathrm{Fe}_{3} \mathrm{O}_{4} @ \mathrm{C}$ catalyzing heterogeneous UV-Fenton system for tetracycline removal with a focus on optimization by a response surface method, J. Photochem. Photobiol., A, 2016, 314, 178.

30 X. D. Zhu, Y. C. Liu, F. Qian, C. Zhou, S. C. Zhang and J. M. Chen, Preparation of magnetic porous carbon from waste hydrochar by simultaneous activation and magnetization for tetracycline removal, Bioresour. Technol., 2014, 154, 209.

31 X. T. Zhang, J. C. Shen, N. Zhuo and W. B. Yang, Interactions between antibiotics and graphene-based materials in water: A comparative experimental and theoretical investigation, ACS Appl. Mater. Interfaces, 2016, 8, 24273.

32 Y. Yu, W. Wang, J. Shi, S. Y. Zhu and Y. C. Yan, Enhanced levofloxacin removal from water using zirconium (IV) loaded corn bracts, Environ. Sci. Pollut. Res., 2017, 24, 10685.

33 S. Z. Yi, B. Gao, Y. Y. Sun and X. Hu, Removal of levofloxacin from aqueous solution using rice-husk and wood-chip biochars, Chemosphere, 2016, 150, 694.

34 B. H. Huang, Y. G. Liu, B. Li, S. B. Liu, G. M. Zeng, Z. W. Zeng, X. H. Wang, Q. M. Ning, B. H. Zheng and C. P. Yang, Effect of $\mathrm{Cu}$ (II) ions on the enhancement of tetracycline adsorption by $\mathrm{Fe}_{3} \mathrm{O}_{4} @ \mathrm{SiO}_{2}$-Chitosan/graphene oxide nanocomposite, Carbohydr. Polym., 2017, 157, 576.

35 Y. Gao, Y. Li, L. Zhang, H. Huang, J. J. Hu, S. M. Shah and X. G. Su, Adsorption and removal of tetracycline antibiotics from aqueous solution by graphene oxide, J. Colloid Interface Sci., 2012, 368, 540.

36 A. C. Martins, O. Pezoti, A. L. Cazetta, K. C. Bedin, D. A. S. Yamazaki, G. F. G. Bandoch, T. Asefa, J. V. Visentainer and V. C. Almeida, Removal of tetracycline by $\mathrm{NaOH}$-activated carbon produced from macadamia nut shells: Kinetic and equilibrium studies, Chem. Eng. J., 2015, 260, 2-91.

37 R. Pai, A. Singh, S. Simotwo and V. Kalra, In situ grown iron oxides on carbon nanofibers as reestanding anodes in aqueous supercapacitors, Adv. Eng. Mater., 2018, 20, 1.

38 A. P. Grosvenor, B. A. Kobe and N. S. Mcityre, Studies of the oxidation of iron by air after being xposed to water vapour using angle-resolved x-ray hotoelectron spectroscopy and QUASES, Surf. Interface Anal., 2004, 36, 1637.

39 H. Y. Hou, Z. P. Dai, X. X. Liu, Y. Yao, Q. S. Liao, C. Y. Yu and D. D. Li, Reutilization of the expired tetracycline for lithium ion battery anode, Sci. Total Environ., 2018, 630, 495.

40 C. Ling, F. Q. Liu, C. Xu, T. P. Chen and A. M. Li, An integrative technique based on synergistic coremoval and sequential recovery of copper and tetracycline with dual functional chelating resin: Roles of amine and carboxyl groups, ACS Appl. Mater. Interfaces, 2013, 5, 11808.

41 E. T. Vandenberg, L. Bertilsson, B. Liedberg, K. Uvdal, R. Erlandsson, H. Elwing and I. Lundström, Structure of 3aminopropyl triethoxy silane on silicon oxide, $J$. Colloid Interface Sci., 1991, 147, 103. 
42 S. Kerber, J. J. Bruckner, K. Wozniak and T. L. Barr, The nature of hydrogen in x-ray photoelectron spectroscopy: General patterns from hydroxides to hydrogen bonding, $J$. Vac. Sci. Technol., A, 1996, 14, 1314.

43 R. Berger, G. Resnati, P. Metrangolo, E. Weber and J. Hulliger, Organic fluorine compounds: a great opportunity for enhanced materials properties, Chem. Soc. Rev., 2011, 40, 3496.

44 J. E. Schaff and J. T. Roberts, Structure sensitivity in the surface chemistry of ice: Acetone adsorption on amorphous and crystalline ice films, J. Phys. Chem., 1994, 98, 6900 .

45 M. A. Henderson, S. A. Joyce and J. Rustad, Interaction of water with the $(1 \times 1)$ and $(2 \times 1)$ surfaces of $\alpha-\mathrm{Fe}_{2} \mathrm{O}_{3}(012)$, Surf. Sci., 1988, 417, 66.

46 T. Iwasita and F. C. Nart, In situ infrared spectroscopy at electrochemecal interfaces, Prog. Surf. Sci., 1997, 55, 271.

47 K. Kandori, J. Sakai and T. Ishikawa, Definitive effects of chloride ions on the formation of spherical hematite particles in a forced hydrolysis reaction, Phys. Chem. Chem. Phys., 2000, 2, 3293.

48 C. Song, X. F. Sun, S. F. Xing, P. F. Xia, Y. J. Shi and S. G. Wang, Characterization of the interactions between tetracycline antibiotics and microbial extracellular polymeric substances with spectroscopic approaches, Environ. Sci. Pollut. Res. Int., 2014, 21, 1786.
49 Z. F. Jiang, J. M. Xie, D. L. Jiang, Z. X. Yan, J. J. Jing and D. Liu, Enhanced adsorption of hydroxyl contained/anionic dyes on non functionalized $\mathrm{Ni@SiO} \mathrm{S}_{2}$ core-shell nanoparticles: Kinetic and thermodynamic profile, Appl. Surf. Sci., 2014, 292, 301.

50 P. Liu, W. J. Liu, H. Jiang, J. J. Chen, W. W. Li and H. Q. Yu, Modification of bio-char derived from fast pyrolysis of biomass and its application in removal of tetracycline from aqueous solution, Bioresour. Technol., 2012, 121, 235.

51 J. Kang, H. J. Liu, Y. M. Zheng, J. Qu and J. P. Chen, Systematic study of synergistic and antagonistic effects on adsorption of tetracycline and copper onto a chitosan, $J$. Colloid Interface Sci., 2010, 344, 117.

52 E. K. Efthimiadou, N. Katsaros, A. Karaliota and G. Psomas, Synthesis, characterization, antibacterial activity, and interaction with DNA of the vanadyl-enrofloxacin complex, Bioorg. Med. Chem. Lett., 2007, 17, 1238.

53 Q. Liu, L. B. Zhong, Q. B. Zhao, C. Frear and Y. M. Zheng, Synthesis of $\mathrm{Fe}_{3} \mathrm{O}_{4} /$ Polyacrylonitrile composite electrospun nanofiber mat for effective adsorption of tetracycline, ACS Appl. Mater. Interfaces, 2015, 7, 14573.

54 C. Gu and K. G. Karthkeyan, Sorption of the antimicrobial ciprofloxacin to aluminum and iron hydrous oxides, Environ. Sci. Technol., 2005, 39, 9166.

$55 \mathrm{P}$. Trivedi and D. Vasudevan, Spectroscopic investigation of ciprofloxacin speciation at the goethite-water interface, Environ. Sci. Technol., 2007, 41, 3153. 